\title{
Laboratory investigation of capillary trapping under mixed-wet conditions
}

\author{
Y. Tanino ${ }^{1}$ and M. J. Blunt ${ }^{2}$ \\ Received 16 December 2012; revised 25 March 2013; accepted 1 June 2013; published 29 July 2013.
}

[1] Remaining oil saturation established by waterflooding was measured in Indiana limestone in its original, water-wet state and under mixed-wet conditions established by adding organic acid to the oil phase. The porous plate technique was used to establish initial oil saturations ranging from $S_{\text {nwi }}=0.23$ to 0.93 under capillary-dominated conditions. For water-wet conditions, the residual oil saturation increased linearly with its initial saturation. In contrast, the remaining oil saturation under mixed-wet conditions, $S_{\mathrm{nw}}$, displayed three distinct regimes. First, $S_{\text {nw }}$ increased with its initial saturation up to $S_{\text {nwi }}=0.58$. Next, $S_{\text {nw }}$ decreased from $S_{\text {nwi }}=0.58$ to 0.76 . Finally, $S_{\text {nw }}$ increased again as $S_{\text {nwi }}$ approached one. The nonmonotonic dependence of $S_{\text {nw }}$ on $S_{\text {nwi }}$ at $S_{\text {nwi }}>0.5$ is well described by a concaveup quadratic function, and may be a salient feature of mixed-wet rocks.

Citation: Tanino, Y., and M. J. Blunt (2013), Laboratory investigation of capillary trapping under mixed-wet conditions, Water Resour. Res., 49, 4311-4319, doi:10.1002/wrcr.20344.

\section{Introduction}

[2] As a wetting phase displaces a nonwetting phase in a porous medium, a portion of the latter becomes immobilized by capillary forces in the form of discontinuous porescale ganglia. It is this phenomenon, known as capillary trapping, that prevents the complete extraction of nonaqueous phase liquid (NAPL) contaminants from aquifers and oil from geological reservoirs. In the context of carbon storage, capillary trapping renders a fraction of the injected $\mathrm{CO}_{2}$ immobile against advection [Iglauer et al., 2011].

[3] Capillary trapping is controlled primarily by the pore structure, wettability, and properties of the fluids and the flow. This paper considers the impact of wettability on capillary trapping in two-phase systems, focusing specifically on mixed-wet conditions. A mixed-wet state is where the porous medium exhibits pore-scale and subpore-scale heterogeneity in wettability such that parts of the pore surface are wetting to the nonaqueous phase while the rest is wetting to the aqueous phase. For example, many oil reservoirs are believed to be mixed wet [e.g., Wood et al., 1991; Sutanto et al., 1990; Øren et al., 1998; Jerauld and Rathmell, 1997]. Here, the heterogeneity in wettability emerges from the preferential migration of oil into larger pores in reservoirs which are initially water-wetting, and the subsequent alteration of grain surfaces in contact with the oil to an oil-wetting state by, e.g., asphaltene adsorption [Kaminsky et al., 1993]. Under this conceptual framework, the remaining surfaces, in the corners of pores and in smaller

\footnotetext{
${ }^{1}$ School of Engineering, University of Aberdeen, Aberdeen, UK.

${ }^{2}$ Department of Earth Science and Engineering, Imperial College London, London, UK.

Corresponding author: Y. Tanino, School of Engineering, University of Aberdeen, Aberdeen AB24 3UE, UK. (ytanino@abdn.ac.uk).

C2013. American Geophysical Union. All Rights Reserved. 0043-1397/13/10.1002/wrcr.20344
}

pores, remain strongly water wet (see Anderson [1986] for a review). By analogy, NAPLs may render a contaminated aquifer mixed wet [Powers and Tamblin, 1995; Powers et al., 1996; Dwarakanath et al., 2002]. At a $\mathrm{CO}_{2}$ storage site, exposure to $\mathrm{CO}_{2}$ may alter the wettability of the grain surface by, e.g., dissolving the surface locally and enhancing the surface roughness at the micron-scale [Espinoza and Santamarina, 2010] or exposing a different mineral [Wang et al., 2012]. Here, wettability is expected to change as the geochemical reaction progresses.

[4] It is well established that the fractional volume of nonwetting phase remaining in a water-wet rock after waterflooding (aqueous phase injection) increases monotonically with its initial saturation [e.g., Stegemeier, 1977; Land, 1968; Pentland et al., 2011; Tanino and Blunt, 2012]. In contrast, the dependence of the nonwetting phase saturation on its initial saturation under mixed-wet conditions has not been studied comprehensively: existing data are focused on $S_{\text {nwi }}>0.65$, where $S_{\text {nwi }}$ is the fractional volume of the pore space of the rock initially occupied by the nonwetting phase [Salathiel, 1973; Graue et al., 1999]. Nevertheless, it has been shown that waterflooding continues to displace oil in rocks exposed to crude oil even after 5-10 pore volumes (pv) of injection [Salathiel, 1973; Zhou et al., 2000; Jadhunandan and Morrow, 1995]. This behavior is characteristic of mixed-wet conditions [Anderson, 1987] and is attributed to the oil remaining connected within the rock in the form of thin films or layers along the grain surface [Iglauer et al., 2012] even at low saturations [Salathiel, 1973]. We refer to the nonwetting phase saturation in a mixed-wet system during waterflooding as remaining saturation, to differentiate it from the asymptotic residual state in which the nonwetting phase is fully disconnected.

[5] This paper presents laboratory measurements of the remaining nonwetting (nonaqueous) phase saturation in Indiana limestone in its original, water-wet state, and under mixed-wet conditions. The nonwetting phase was oil, and 
the wetting phase was brine. The porous plate technique was used to establish the full range of $S_{\text {nwi }}$. Mixed-wet conditions were established using a solution of $1.5 \mathrm{wt} . \%$ cyclohexanepentanoic acid in $n$-decane as the nonwetting phase, which has previously been shown to render calcite less water-wetting at room temperature [Wu et al., 2008].

\section{Materials and Methods}

\subsection{Rock}

[6] The porous medium was Indiana limestone, selected because of its homogeneity at the core-scale $(\mathrm{cm})$, strength, and commercial availability. In addition, the pore structure and flow phenomena in this rock have been studied extensively [e.g., Zhu et al., 2010; Churcher et al., 1991; Wardlaw and Taylor, 1976; Wardlaw et al., 1987; Mair et al., 1999; Hart and Wang, 1995; Tanino and Blunt, 2012; ElMaghraby and Blunt, 2013]. Indiana limestone is $99.0 \%$ calcite and $1.0 \%$ quartz (Weatherford Laboratories, East Grinstead) and is naturally water-wetting. Porosity and brine permeability were measured to be $\phi=0.133 \pm 0.002$ (s.e., 10 samples) and $k=(2.0 \pm 0.2) \times 10^{-15} \mathrm{~m}^{2}$ (s.e., 9 samples), respectively.

[7] The pore size distribution of the rock, as characterized by nuclear magnetic resonance transverse relaxation times, is reported by Tanino and Blunt [2012]. Similarly, Figure 1 presents mercury/vapor drainage capillary pressure measurements, $P_{\mathrm{c}, \mathrm{Hg}}$, and the pore entry size distribution derived from them previously by Tanino and Blunt [2012]. The pore entry size distribution is plotted as $r_{p} f\left(r_{p}\right)$, where $r_{p}$ is the equivalent pore throat radii of the capillary pressure as calculated using the Young-Laplace equation and an assumed contact angle of $\theta_{\mathrm{Hg}}=130^{\circ}$ and interfacial tension of $\sigma_{\mathrm{Hg}}=485 \mathrm{mNm}^{-1}$ [Winslow, 1978; Good and Mikhail, 1981],

$$
r_{p}=\frac{2 \sigma_{\mathrm{Hg}}\left|\cos \theta_{\mathrm{Hg}}\right|}{P_{\mathrm{c}, \mathrm{Hg}}},
$$

and

$$
f\left(r_{p}\right)=\frac{\mathrm{d} S_{w}}{\mathrm{~d} r_{p}}
$$

is the probability distribution function for pores with a capillary entry pressure corresponding to $r_{p}$.

\subsection{Aqueous and Nonaqueous Phases}

[8] The same wetting phase was used in all experiments and was prepared by mixing an aqueous solution of $5 \mathrm{wt} . \%$ sodium chloride and $1 \mathrm{wt} . \%$ potassium chloride with some crushed rock on a magnetic stirrer for a minimum of $48 \mathrm{~h}$. The brine was subsequently filtered, then degassed by vacuum. For the measurement of capillary trapping under mixed-wet conditions, a solution of 1.5 wt. $\%$ cyclohexanepentanoic acid (Sigma Aldrich, 98\%) in $n$-decane was used as the nonwetting phase. For unaltered (i.e., water-wet) conditions, either pure $n$-decane (Sigma Aldrich, $\geq 99 \%$ ) or $n$-octane (Sigma Aldrich, $\geq 99 \%$ ) was used instead.

[9] The basic properties of the liquids are presented in Table 1. The density, $\rho$, of all liquids were measured at $20^{\circ} \mathrm{C}$ (Anton Paar DMA 48 or 500). The kinematic viscos-
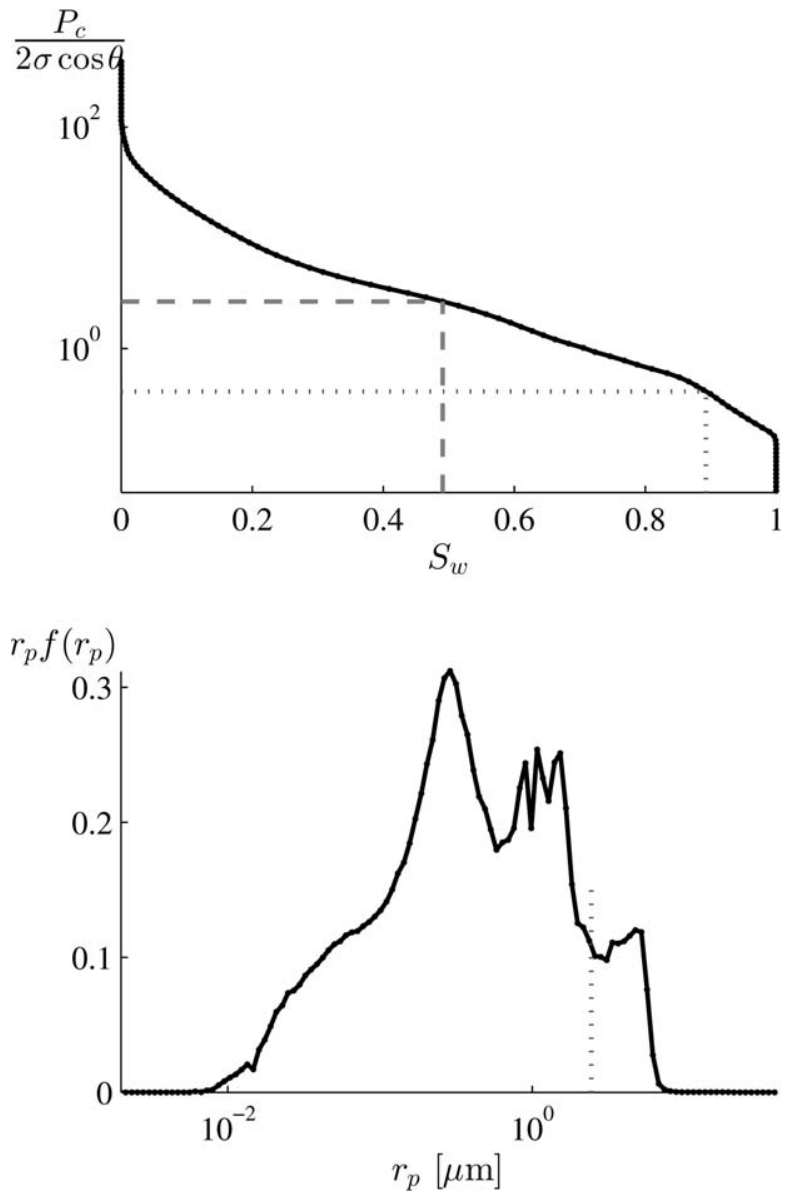

Figure 1. (a) Normalized drainage capillary pressure $\left(P_{\mathrm{c}, \mathrm{Hg}} /\left(2 \sigma_{\mathrm{Hg}}\left|\cos \theta_{\mathrm{Hg}}\right|\right)\left(\mu \mathrm{m}^{-1}\right)\right)$ required to achieve a given wetting phase saturation $S_{w}$ and (b) the corresponding pore entry size distribution $\left(r_{p} f\left(r_{p}\right)\right)$ as reported in Tanino and Blunt [2012]. Dashed lines depict $\left(S_{w}\right.$, $\left.P_{\mathrm{b}, \mathrm{Hg}} /\left(2 \sigma_{\mathrm{Hg}}\left|\cos \theta_{\mathrm{Hg}}\right|\right)\right)=\left(0.49,2.7 \mu \mathrm{m}^{-1}\right) \quad$ [cf. equation (3)]. Dotted lines depict $S_{w}=1-S_{\text {nwi,c }}=0.89$ and the corresponding $P_{\mathrm{c}, \mathrm{Hg}} /\left(2 \sigma_{\mathrm{Hg}}\left|\cos \theta_{\mathrm{Hg}}\right|\right)=0.41 \mu \mathrm{m}^{-1}$ (Figure 1a) and $r_{p}=2.4 \mu \mathrm{m}$ (Figure 1b).

ity of the $n$-decane + organic acid solution was measured using a glass capillary viscometer (Rheotek Type BS/U Utube viscometer, size A) to be $\nu=1.20 \mathrm{~mm}^{2} \mathrm{~s}^{-1}$; the corresponding dynamic viscosity, $\mu$, is $\mu=\nu \rho=0.880 \mathrm{mPa}$. The interfacial tension of each oil phase with the brine, $\sigma$, was measured using the pendant drop method (DSA Easydrop, Krss GmbH, Hamburg).

\subsection{Coreflood Procedure}

[10] Experiments were performed on 10 cylindrical rock samples of diameter $37.69 \pm 0.01 \mathrm{~mm}$ and length that varied between $L=75.66 \pm 0.02 \mathrm{~mm}$ and $89.90 \pm 0.02 \mathrm{~mm}$. The samples were housed in custom-made, horizontal, Hasslertype pressure cells with radial confining pressure during fluid injection.

[11] Liquids were injected using high-precision syringe pumps (Teledyne ISCO 1000D). The microscopic capillary number, $\mathrm{Ca}=\mu U / \sigma$, and the macroscopic capillary number proposed by Hilfer and Oren [1996], 
Table 1. Basic Properties of the Fluids ${ }^{\mathrm{a}}$

\begin{tabular}{|c|c|c|c|c|}
\hline & Wetting Phase & $n$-Octane & $n$-Decane & $\begin{array}{c}1.5 \text { wt. \% Cyclohexanepentanoic } \\
\text { Acid in } n \text {-Decane }\end{array}$ \\
\hline$\mu(\mathrm{mPa} \mathrm{s})$ & $1.0903^{\mathrm{b}}$ & $0.508^{\mathrm{c}}$ & $0.838^{\mathrm{c}}$ & 0.880 \\
\hline$\rho\left(\mathrm{kg} \mathrm{m}^{-3}\right)$ & $1032.0-1059.0$ & 702.6 & 729.5 & $732.5 \pm 0.02$ (s.e.) \\
\hline$\sigma\left(\mathrm{mN} \mathrm{m}^{-1}\right)$ & - & $51.64 \pm 0.04^{\mathrm{d}}$ & $52.3 \pm 0.4$ & $27.52 \pm 0.08$ \\
\hline
\end{tabular}

${ }^{\text {a } U n l e s s ~ o t h e r w i s e ~ n o t e d, ~} \sigma$ is the interfacial tension of the respective nonwetting phase with the limestone-equilibrated brine; the uncertainty is standard error of the mean.

${ }^{\mathrm{b}}$ For $5.8 \mathrm{wt} . \%$ aqueous sodium chloride solution at $100 \mathrm{kPa}, 293.2 \mathrm{~K}$ [Kestin et al., 1981].

${ }^{\mathrm{c} A t} 298 \mathrm{~K}$ [Haynes, 2011].

${ }^{\mathrm{d}} \sigma$ with water at $293.2 \pm 0.1 \mathrm{~K}$ [Zeppieri et al., 2001].

$$
\langle\mathrm{Ca}\rangle=\frac{\mu U L / k}{\left(P_{\mathrm{b}, \mathrm{Hg}} / \sigma_{\mathrm{Hg}}\right) \sigma},
$$

where $\mu$ is the viscosity of the injected fluid, $U$ is its volumetric flow rate per unit cross-sectional area of the rock sample, and $\left(S_{w}, P_{\mathrm{b}, \mathrm{Hg}} / \sigma_{\mathrm{Hg}}\right)=\left(0.49,3.4 \mu \mathrm{m}^{-1}\right)$ is the inflection point in the mercury/vapor drainage capillary pressure curve (Figure 1a, dashed) were maintained at $\mathrm{Ca}<10^{-6}$ and $\langle\mathrm{Ca}\rangle \leq O(1)$ to ensure capillary-dominated conditions [Chatzis and Morrow, 1984; Hilfer and Oren, 1996].

[12] Prior to each experiment, the rock sample was saturated with brine to mimic the initial state of geological reservoirs. To do so, air was removed from the test sample by alternately purging with gaseous $\mathrm{CO}_{2}$ and applying a vacuum. The sample was then flooded with 131 to $310 \mathrm{pv}$ of degassed brine. The absolute permeability, $k$, was determined during this step by changing the flow rate several times and, at each flow rate, measuring the pressure drop across the length of the core once steady state was achieved. The permeability was calculated as

$$
k=\mu_{\mathrm{w}} \frac{\mathrm{d} U}{\mathrm{~d}(\Delta P / L)},
$$

where $\mu_{\mathrm{w}}$ is the viscosity of the brine and $\Delta P$ is the magnitude of the pressure difference across the core. $\mathrm{d} U / \mathrm{d}(\Delta P / L)$ is taken as the gradient of the line of regression of $U$ on $\Delta P / L$. The uncertainty in $k$ is taken as that of $\mathrm{d} U / \mathrm{d}(\Delta P / L)$ as estimated according to Taylor [1997, Chapter 8]. The pore volume, hence $\phi$, was determined from the difference in the mass of the core between its dry state prior to the experiment and its brine-saturated state.

\subsubsection{Capillary Trapping Under Mixed-Wet \\ Conditions}

[13] Each experiment consists of a sequence of fluid displacement, as described below, that mimic that associated with geological carbon storage in saline aquifers and secondary oil production. After each step, the sample was removed from the Hassler cell and weighed. The corresponding oil saturation was determined from the difference in the weight of the core from its dry state. The details of specific steps are described in Tanino and Blunt [2012] and are thus omitted here.

\subsubsection{Primary Drainage}

[14] Initial oil saturation, $S_{\text {nwi }}$, was established by injecting the oil phase at constant pressure from one face of the rock sample against a hydrophilic permeable disk (Weatherford Laboratories, Stavanger) placed immediately downstream of the opposite face. The disk retained the oil phase

inside the sample while allowing brine through. At equilibrium, flow ceased and, accordingly, a uniform capillary pressure, $P_{c}$, and oil saturation were established across the length of the core. Each experiment is associated with one drainage $P_{c}$, which in turn corresponds to a unique $S_{\text {nwi }}$. The duration of primary drainage ranged from 10 to 29 days. The maximum capillary number was constrained at $\langle\mathrm{Ca}\rangle=2$.

\subsubsection{Spontaneous Imbibition}

[15] After $S_{\text {nwi }}$ was established, the core was submerged in brine in a custom-made glass Amott cell (Soham Scientific, Ely) for a minimum of 27 days to allow the brine to spontaneously imbibe into the rock. The length of the core is sufficiently short that hydrostatic pressure may be neglected, and $P_{c}=0$ everywhere. Accordingly, the remaining oil saturation at the end of this step is denoted by $S_{\mathrm{nw}}^{P_{c}=0}$.

\subsubsection{Waterflooding}

[16] Subsequently, the core was reinserted into a Hassler cell for waterflooding. Brine was injected into the sample at a constant volumetric flow rate of $0.100 \mathrm{~mL} \mathrm{~min}^{-1}$, which corresponds to $U=1.5 \times 10^{-3} \mathrm{~mm} \mathrm{~s}^{-1}$; the macroscopic capillary number varied from $\langle\mathrm{Ca}\rangle=0.47$ to 1.1 . At selected times, the core was removed from the Hassler cell and weighed to determine the remaining oil saturation, $S_{\text {nw }}(n)$, where $n$ is the cumulative volume of brine injection in units of pore volume (pv). The asymptotic (large $n$ ) limit of $S_{\text {nw }}(n)$ is denoted by $S_{\text {nwr }}$, where the subscript $\mathrm{r}$ denotes residual state.

[17] The effective relative permeability of the sample to the brine after $100 \mathrm{pv}$ of brine injection was estimated as

$$
k_{\mathrm{rw}}^{100 \mathrm{pv}}=\frac{\mu_{\mathrm{w}}}{k} \frac{U}{\Delta P / L},
$$

where $\Delta P$ denotes the pressure difference across the length of the core after $n=100 \mathrm{pv}$ at a single $U$.

\subsubsection{Capillary Trapping Under Water-Wet \\ Conditions}

[18] The procedure could be simplified for water-wet conditions, because $S_{\text {nw }}(n)$ asymptotes after 1-2 pv of brine injection [e.g., Salathiel, 1973; Jadhunandan and Morrow, 1995; Zhou et al., 2000; Mungan, 1966; Wang, 1988]. Waterflooding from a given $S_{\text {nwi }}$ rapidly establishes a unique residual oil saturation, $S_{\mathrm{nwr}}^{\mathrm{ww}}$, that is independent of waterflood rate or cumulative volume injected as long as capillary-dominated conditions are maintained. Accordingly, $S_{\mathrm{nwr}}^{\mathrm{ww}}$ was measured once or twice only, and permeability at $S_{\mathrm{nwr}}^{\mathrm{ww}}$, denoted by $k\left(S_{\mathrm{nwr}}^{\mathrm{ww}}\right)$, was calculated using 
Table 2. Summary of Coreflood Experiments Under Water-Wet Conditions, in Order of Increasing $S_{\text {nwi }}{ }^{a}$

\begin{tabular}{lcccccr}
\hline Experiment & $\phi$ & $k\left(\times 10^{-15} \mathrm{~m}^{2}\right)$ & $S_{\mathrm{nwi}}$ & $S_{\mathrm{nwr}}^{\mathrm{ww}}$ & $k_{\mathrm{rw}}^{\mathrm{ww}}$ & $k_{\mathrm{rw}}^{\mathrm{ww}} /\left(1-S_{\mathrm{nwr}}^{\mathrm{ww}}\right)$ \\
\hline $\mathrm{A}^{\mathrm{b}}$ & 0.131 & $3.12 \pm 0.07$ & 0.23 & $0.12 \pm 0.02$ & $0.280 \pm 0.007$ & $0.318 \pm 0.008$ \\
$\mathrm{~B}^{\mathrm{c}}$ & 0.136 & $\mathrm{~N} / \mathrm{A}$ & 0.40 & $0.28 \pm 0.03$ & $0.178 \pm 0.002$ & $0.246 \pm 0.002$ \\
$\mathrm{C}$ & 0.121 & 1.6 & 0.76 & 0.38 & $\mathrm{~N} / \mathrm{A}$ & $\mathrm{N} / \mathrm{A}$ \\
$\mathrm{D}^{\mathrm{b}}$ & 0.139 & $2.3 \pm 0.1$ & 0.86 & $0.47 \pm 0.01$ & $0.101 \pm 0.005$ & $0.189 \pm 0.009$ \\
$\mathrm{E}$ & 0.136 & $2.13 \pm 0.02$ & 0.91 & 0.48 & N/A & N/A \\
\hline
\end{tabular}

${ }^{\mathrm{a}}$ The uncertainty in $S_{\mathrm{nwr}}^{\mathrm{ww}}$ is the difference in measured $S_{\mathrm{nwr}}^{\mathrm{ww}}$ before and after the residual-state permeability measurements. The fractional uncertainty in $k_{\mathrm{rw}}^{\mathrm{ww}}=k\left(S_{\mathrm{nwr}}^{\mathrm{ww}}\right) / k$ is approximated as the sum of the fractional uncertainty of $k$ and $k\left(S_{\mathrm{nwr}}^{\mathrm{ww}}\right)$, which in turn represent the uncertainty in the respective $\mathrm{d} U / \mathrm{d}(\Delta P / L)$ (equation (4)). The oil phase was $n$-octane in experiments B and $\mathrm{C}$, and $n$-decane in others.

${ }^{\mathrm{b}}$ Previously reported in Tanino and Blunt [2012].

${ }^{c}$ Absolute permeability was not measured on the core used in this experimental run. $k=(2.13 \pm 0.02) \times 10^{-15} \mathrm{~m}^{2}$ of a core with a similar $\phi$ is used instead to calculate $k_{\mathrm{rw}}^{\mathrm{ww}}$ and $\langle\mathrm{Ca}\rangle$.

equation (4) instead of equation (5), i.e., $\Delta P$ and the corresponding $U$ were measured at multiple flow rates. At least $n=11 \mathrm{pv}$ of brine was injected before the first $S_{\mathrm{nwr}}^{\mathrm{ww}}$ measurement was taken; the second $S_{\mathrm{nwr}}^{\mathrm{ww}}$ measurement was taken after $n=49-69$ pv of cumulative brine injection. Also, the residual saturation established by waterflooding is the same as that established by spontaneous imbibition under strongly water-wet conditions [Johannesen et al., 2007; Zhou et al., 2000]. Accordingly, $S_{\text {nw }}^{P_{c}=0}$ was not measured explicitly.

[19] The maximum capillary number during primary drainage was constrained at $\langle\mathrm{Ca}\rangle=0.43-0.73$. The maximum capillary number reached during waterflooding was $\langle\mathrm{Ca}\rangle=0.54$.

\section{Results}

\subsection{Permeability to Brine at Remaining Oil Saturation}

[20] It can be readily shown that the relative permeability of an idealized porous medium comprised of parallel, identical capillary tubes during waterflood, $k_{\mathrm{rw}}$, is equal to fractional volume of the pore space that conducts brine, i.e., $k_{\mathrm{rw}}=1-S_{\mathrm{nw}}$, with the assumption that a tube can only be occupied by one phase [Dullien, 1991, Chapter 3.2]. The deviation of $k_{\mathrm{rw}}$ from $1-S_{\mathrm{nw}}$ is thus a measure of the bias in the spatial distribution of the oil phase during waterflood. For example, in strongly water-wet systems, the nonwetting phase is retained in the larger pores and the wetting phase flows through the smaller pores [Iglauer et al., 2010, 2011] and, accordingly, $k_{\mathrm{rw}} \ll 1-S_{\mathrm{nw}}$.

[21] The relative permeability to brine at remaining/residual oil saturation under water-wet conditions, $k_{\mathrm{rw}}^{\mathrm{ww}}$, and under mixed-wet conditions, $k_{\mathrm{rw}}^{100 \mathrm{pv}}$, are presented in Tables 2 and 3 , respectively. Both $k_{\mathrm{rw}}^{\mathrm{ww}}$ and $k_{\mathrm{rw}}^{100 \mathrm{pv}}$ are smaller than one for all $S_{\mathrm{nw}}>0$, as expected. The small $k_{\mathrm{rw}}^{\mathrm{ww}} /\left(1-S_{\mathrm{nwr}}^{\mathrm{ww}}\right) \leq 0.3$ observed in experiments using pure $n$-octane or $n$-decane as the oil phase is consistent with a strongly water-wetting system [Tanino and Blunt, 2012; Skauge and Ottesen, 2002; Oak et al., 1990; Amaefule and Handy, 1982]. Under mixed-wet conditions, the relative permeability was larger $\left[k_{\mathrm{rw}}^{100 \mathrm{pv}} /\left(1-S_{\mathrm{nw}}^{100 \mathrm{pv}}\right) \geq 0.5\right]$. An elevated relative permeability implies that brine was not restricted to the smallest pores, and thus confirms that the presence of organic acid in the oil phase has altered the wettability of the rock. Combined, $k_{\mathrm{rw}}^{100 \mathrm{pv}}$ was broadly a factor of 4-5 larger than $k_{\mathrm{rw}}^{\mathrm{ww}}$.

[22] We emphasize that Darcy behavior could not be confirmed under mixed-wet conditions, because $S_{\text {nw }}$, hence the flow velocity for a given pressure gradient, is a function of the cumulative volume of brine injected. Thus, the permeability to brine at remaining oil saturation reported in Table 3 is strictly valid only at $n=100$ pv of cumulative brine injection at $U=1.5 \times 10^{-3} \mathrm{~mm} \mathrm{~s}^{-1}$. In contrast, the flow velocity increased linearly with pressure gradient for all $S_{\mathrm{nwr}}^{\mathrm{ww}}$ considered under water-wet conditions [e.g., Tanino and Blunt, 2012, Figure 8]. Accordingly, the permeability at $S_{\text {nwr }}^{\mathrm{ww}}$ reported in Table 2 is independent of $U$ and $n$ provided that capillary-dominated conditions are maintained.

\subsection{Remaining/Residual Oil Saturation}

[23] Here we compare the dependence of remaining oil saturation on initial saturation under mixed-wet conditions with that under water-wet conditions.

\subsubsection{Water-Wet Conditions}

[24] First, we consider trapping under water-wet conditions. Figure 2 presents the residual oil saturation under water-wet conditions, $S_{\mathrm{nwr}}^{\mathrm{ww}}$, measured in the present study (squares). The data coincide with measurements of $S_{\mathrm{nw}}^{P_{c}=0}$ established by spontaneous imbibition in Indiana limestone of similar $\phi(=0.140)$ and $k\left(=10^{-15} \mathrm{~m}^{2}\right)$ by Wardlaw and Taylor [1976] (diamonds). The good agreement is consistent with previous observations that $S_{\mathrm{nw}}^{P_{c}=0}=S_{\mathrm{nwr}}^{\mathrm{ww}}$ under water-wet conditions (cf. section 2.3.2).

[25] In both data sets, residual saturation increases linearly with $S_{\text {nwi }}$ over the range of $S_{\text {nwi }}$ considered, namely $0.21 \leq S_{\text {nwi }} \leq 0.91$. A linear regression on all data shown yields a line of best-fit in the least-squares sense of (solid line)

$$
S_{\mathrm{nwr}}^{\mathrm{ww}}=(0.06 \pm 0.02)+(0.47 \pm 0.04) S_{\mathrm{nwi}} ;
$$

the correlation coefficient is $r=0.980$, indicating a highly significant correlation. Note that equation (6) intersects the $S_{\text {nwr }}^{\mathrm{ww}}=S_{\text {nwi }}$ line at a finite initial saturation of $S_{\text {nwi }}=0.11 \pm 0.03$. Since oil saturation cannot increase during brine injection, this suggests that $S_{\text {nwr }}^{\mathrm{ww}} \approx S_{\text {nwi }}$ (dotted line) below this critical $S_{\text {nwi }}$, which we denote by $S_{\text {nwi,c }}$.

[26] To understand the origin of $S_{\text {nwi,c }}$, we consider the capillary entry size distribution of the rock. From Figure 1, it can be inferred that the capillary pressure required to establish an initial nonwetting phase saturation of 
Table 3. Summary of Coreflood Experiments Under Mixed-Wet Conditions, in Order of Increasing $S_{\text {nwi }}$ a

\begin{tabular}{|c|c|c|c|c|c|c|c|c|c|}
\hline Experiment & $\phi$ & $k\left(\times 10^{-15} \mathrm{~m}^{2}\right)$ & $S_{\text {nwi }}$ & $S_{\mathrm{nw}}^{P_{c}=0}($ days $)$ & $S_{\mathrm{nw}}(n(\mathrm{pv}))$ & $k_{\mathrm{rw}}^{100 \mathrm{pv}}$ & $\frac{k_{\mathrm{rw}}^{100 \mathrm{pv}}}{\left(1-S_{\mathrm{nw}}^{100 \mathrm{pv}}\right)}$ & $\begin{array}{l}\text { Marker in } \\
\text { Figure } 4\end{array}$ & $\begin{array}{l}\text { Best-Fit Power Function } \\
\quad \text { to }\left(n(\mathrm{pv}), S_{\mathrm{nw}}\right) \\
\end{array}$ \\
\hline $\mathrm{F}$ & 0.132 & 1.5 & 0.33 & $0.18(32)$ & $\begin{array}{l}0.19(1) \\
0.14(23) \\
0.12(99) \\
0.12(193) \\
0.13(290)\end{array}$ & 0.59 & 0.67 & square & $S_{\mathrm{nw}}=0.18 n^{-0.080}$ \\
\hline$\overline{\mathrm{G}}$ & 0.129 & $1.74 \pm 0.01$ & 0.58 & $0.48(27)$ & $\begin{array}{l}0.32(1) \\
0.28(25) \\
0.25(100) \\
0.24(217) \\
0.24(299)\end{array}$ & 0.37 & 0.49 & cross & $S_{\mathrm{nw}}=0.32 n^{-0.049}$ \\
\hline$\overline{\mathrm{H}}$ & 0.130 & 2.8 & 0.76 & N/A & $\begin{array}{l}0.43(1) \\
0.27(24) \\
0.23(101) \\
0.21(208)\end{array}$ & 0.79 & 1.0 & circle & $S_{\mathrm{nw}}=0.42 n^{-0.13}$ \\
\hline $\bar{I}$ & 0.133 & $1.64 \pm 0.03$ & 0.91 & $0.79(273)$ & $\begin{array}{l}0.48(2) \\
0.35(25) \\
0.34(100) \\
0.31(216) \\
0.33(299)\end{array}$ & 0.84 & 1.3 & plus & $S_{\mathrm{nw}}=0.48 n^{-0.078}$ \\
\hline $\bar{J}$ & 0.139 & $1.46 \pm 0.02$ & 0.93 & $0.84(34)$ & $\begin{array}{l}0.54(1) \\
0.36(24) \\
0.34(41) \\
0.29(99)\end{array}$ & 0.58 & 0.82 & diamond & $S_{\mathrm{nw}}=0.53 n^{-0.12}$ \\
\hline
\end{tabular}

${ }^{\mathrm{a}}$ The number in brackets under $S_{\mathrm{nw}}^{P_{c}=0}$ is the duration of spontaneous imbibition at the time of $S_{\mathrm{nw}}^{P_{c}=0}$ measurement.

$S_{\text {nwi }}=S_{\text {nwi, }}=0.11$ in this limestone is $P_{c} /(2 \sigma \cos \theta)=$ $0.41 \mu \mathrm{m}^{-1}$ (Figure 1, top). The corresponding $r_{p}=2.4 \mu \mathrm{m}$ (dotted line) falls between the first two peaks in the capillary entry size distribution, suggesting that it is a threshold between the largest, interparticle pores and the smaller, intraparticle pores. Thus, the low $S_{\text {nwi }}\left(<S_{\text {nwi,c }}\right)$ regime is attributed to a state where only large macropores are invaded by the oil during primary drainage such that, during subsequent waterflooding, the brine simply flows through the smaller pores and intraparticle microporosity without expelling oil. In contrast, in the high $S_{\text {nwi }}\left(>S_{\text {nwi,c }}\right)$ regime, oil invades the smaller pores and the constrictions that connect larger pores during primary drainage. This oil is partially expelled during waterflooding, resulting in $S_{\text {nwr }}^{\mathrm{ww}}<S_{\text {nwi }}$.

\subsubsection{Mixed-Wet Conditions}

[27] The remaining oil saturation after spontaneous imbibition $\left(S_{\mathrm{nw}}^{P_{c}=0}\right.$, open circle) is compared with the residual saturation under water-wet conditions $\left(S_{\mathrm{nwr}}^{\mathrm{ww}}\right.$, blue dash-dotted line) in Figure 3a. It is evident that $S_{\text {nw }}^{P_{c}=0}$ increases monotonically with increasing $S_{\text {nwi }}$; a linear regression to the three measurements at $S_{\text {nwi }}>0.5$ yields

$$
S_{\mathrm{nw}}^{P_{c}=0}=(0.96 \pm 0.06) S_{\mathrm{nwi}}-(0.07 \pm 0.05),
$$

with a correlation coefficient of $r=1.00$ (black solid line). Note that $S_{\mathrm{nw}}^{P_{c}=0}$ deviates from this line at low $S_{\mathrm{nwi}}=0.33$ (experiment F), suggesting a regime change at $S_{\text {nwi }} \approx 0.5$; this is more apparent in the waterflood $S_{\text {nw }}$ data, which we consider next.

[28] Consistent with previous observations (cf. section 1), the remaining oil saturation decreased continuously as waterflooding progressed at all $S_{\text {nwi }}$ considered (Figure $4 a$ ). It is expected that, like relative permeability, the rate of oil recovery is very sensitive to the pore structure and the fluid distribution within it, which in turn varies with the evolving oil saturation. Nevertheless, the evolution in each experiment is well described by the best-fit power function in the

Table 4. Coefficients of Equation (9) Fitted to the Waterflood Data ${ }^{a}$

\begin{tabular}{|c|c|c|c|c|c|c|c|c|}
\hline Source & Rock & $\phi$ & $k\left(\times 10^{-15} \mathrm{~m}^{2}\right)$ & $\alpha_{0}$ & $\alpha_{1}$ & $\alpha_{2}$ & $n(\mathrm{pv})$ & Relevant $S_{\text {nwi }}$ Range \\
\hline Present study & Indiana limestone & $0.133 \pm 0.002$ & $2.0 \pm 0.2$ & $\begin{array}{c}\mathrm{N} / \mathrm{A} \\
1.7 \\
1.4 \\
2.3\end{array}$ & $\begin{array}{c}0.63 \pm 0.02 \\
-2.3 \\
-2.0 \\
-3.2\end{array}$ & $\begin{array}{c}-0.04 \pm 0.02 \\
1.05 \\
0.91 \\
1.31\end{array}$ & $\begin{array}{c}0.7-1 \\
23-25 \\
99-101 \\
193-217\end{array}$ & $0.58-0.93$ \\
\hline Salathiel [1973] & Boise sandstone & $0.290 \pm 0.004$ & $1170 \pm 140$ & $\begin{array}{l}2.7 \\
2.4 \\
2.4\end{array}$ & $\begin{array}{l}-3.9 \\
-3.7 \\
-4.0\end{array}$ & $\begin{array}{l}1.7 \\
1.7 \\
1.9\end{array}$ & $\begin{array}{c}1 \\
5 \\
20\end{array}$ & $0.675-1.000$ \\
\hline
\end{tabular}

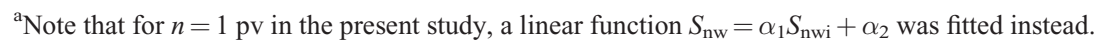




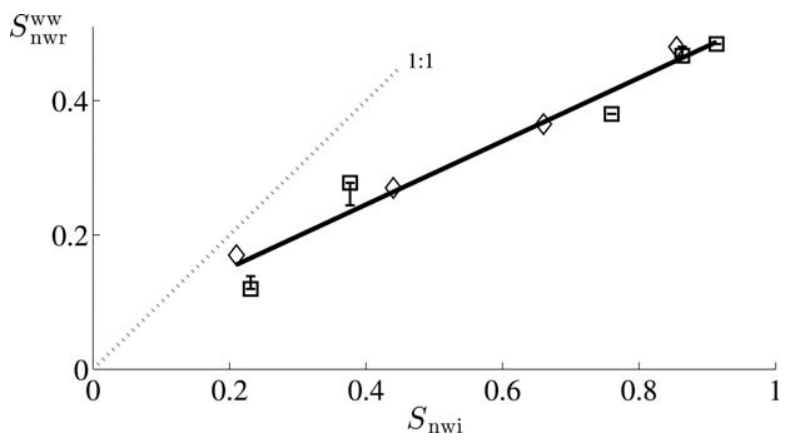

Figure 2. Residual oil saturation as a function of its initial saturation under water-wet conditions $\left(S_{\mathrm{nwr}}^{\mathrm{ww}}\right.$, squares $)$ Vertical bars depict the difference between two $S_{\text {nwr }}^{\mathrm{ww}}$ measurements taken before and after the residual-state permeability measurements; $S_{\mathrm{nwr}}^{\mathrm{ww}}$ was measured only once in experiments $\mathrm{C}\left[\left(S_{\mathrm{nwi}}, S_{\mathrm{nwr}}^{\mathrm{ww}}\right)=(0.76,0.38)\right]$ and $\mathrm{E}[(0.91,0.48)]$. Also shown is the remaining mercury saturation measured in Indiana limestone by Wardlaw and Taylor [1976] (mercury/vapor, diamonds). The solid line is equation (6), the line of best-fit to all data shown.

least-squares sense to the respective data (solid line); the corresponding equations are provided in Table 3 . The exponent in the best-fit functions ranges from -0.078 to -0.13 . Similarly, the remaining oil in a mixed-wet sandstone during waterflooding documented by Salathiel [1973] varies like $S_{\text {nw }} \propto n^{-0.18}$ over $n=2$ to 4600 pv (dotted line).

[29] By extrapolating the best-fit functions to lower $n$ (early times), we can estimate the critical cumulative waterflood volume at which $S_{\text {nw }}$ for a given $S_{\text {nwi }}$ first falls below the equivalent residual saturation under water-wet conditions; the latter is given by $S_{\mathrm{nwr}}^{\mathrm{ww}}$ interpolated from equation (6) for that $S_{\text {nwi }}$. The critical $n$ ranges from $O(0.1)$ to $O(1)$, with the transition occurring at $n=0.17 \mathrm{pv}$ for $S_{\text {nwi }}=0.33$ and $n=1.6 \mathrm{pv}$ for $S_{\text {nwi }}=0.93$ (Figure 4b).

[30] We now consider the dependence of $S_{\text {nw }}(n)$ on $S_{\text {nwi }}$. $S_{\text {nw }}(n)$ at selected cumulative waterflood volumes are presented in Figure $3 \mathrm{a}$. At $n \approx 1 \mathrm{pv}, S_{\mathrm{nw}}$ increases monotonically with $S_{\text {nwi }}$ (green). The data at $S_{\text {nwi }}>0.5$ is well described by the best-fit line (solid green line):

$$
S_{\mathrm{nw}}=(0.63 \pm 0.02) S_{\mathrm{nwi}}-(0.04 \pm 0.02) \text {; }
$$

Equation (8) underestimates $S_{\mathrm{nw}}$ at $S_{\mathrm{nwi}}=0.33$. At larger $n$ considered, $S_{\mathrm{nw}}$ is clearly not monotonic. Specifically, $S_{\mathrm{nw}}$ increases as $S_{\text {nwi }}$ increases from 0.33 to 0.58 , then decreases slightly, then increases again from $S_{\text {nwi }}=0.76$ to 0.93 . Furthermore, $S_{\text {nw }}$ above $S_{\text {nwi }}=0.5$ is well described by a quadratic function of the form

$$
S_{\mathrm{nw}}(n)=\alpha_{0} S_{\mathrm{nwi}}^{2}+\alpha_{1} S_{\mathrm{nwi}}+\alpha_{2},
$$

where coefficients $\alpha_{0}, \alpha_{1}$, and $\alpha_{2}$ are fitted to the data in the least-squares sense (solid lines). Note that $S_{\mathrm{nw}}$ cannot exceed $S_{\text {nw }}$ at earlier times, i.e., equation (9) cannot intersect equation (8). Accordingly, the concave-up profile described by equation (9) is not valid below some threshold $S_{\text {nwi }} \approx 0.5$.
[31] The only existing data of waterflood oil recovery in mixed-wet rock as a function of initial saturation and $n$, in which the initial saturation is established by a fluid displacement sequence representative of those that occur in the field, in the literature are those of Salathiel [1973]. $S_{\mathrm{nw}}$ in a Boise sandstone reported by Salathiel [1973] also displays a quadratic, concave-up dependence at high $S_{\text {nwi }} \geq 0.68$ under mixed-wet conditions (Figure $3 \mathrm{~b}$, dashed line). This is particularly interesting because Boise sandstone and Indiana limestone display distinctly different $S_{\text {nwr }}-S_{\text {nwi }}$ trends under water-wet conditions. Specifically, Indiana limestone displays a bilinear profile (section 3.2.1), while Boise sandstone displays the classic Land [1968]type profile, in which the rate of increase of $S_{\text {nwr }}$ decreases

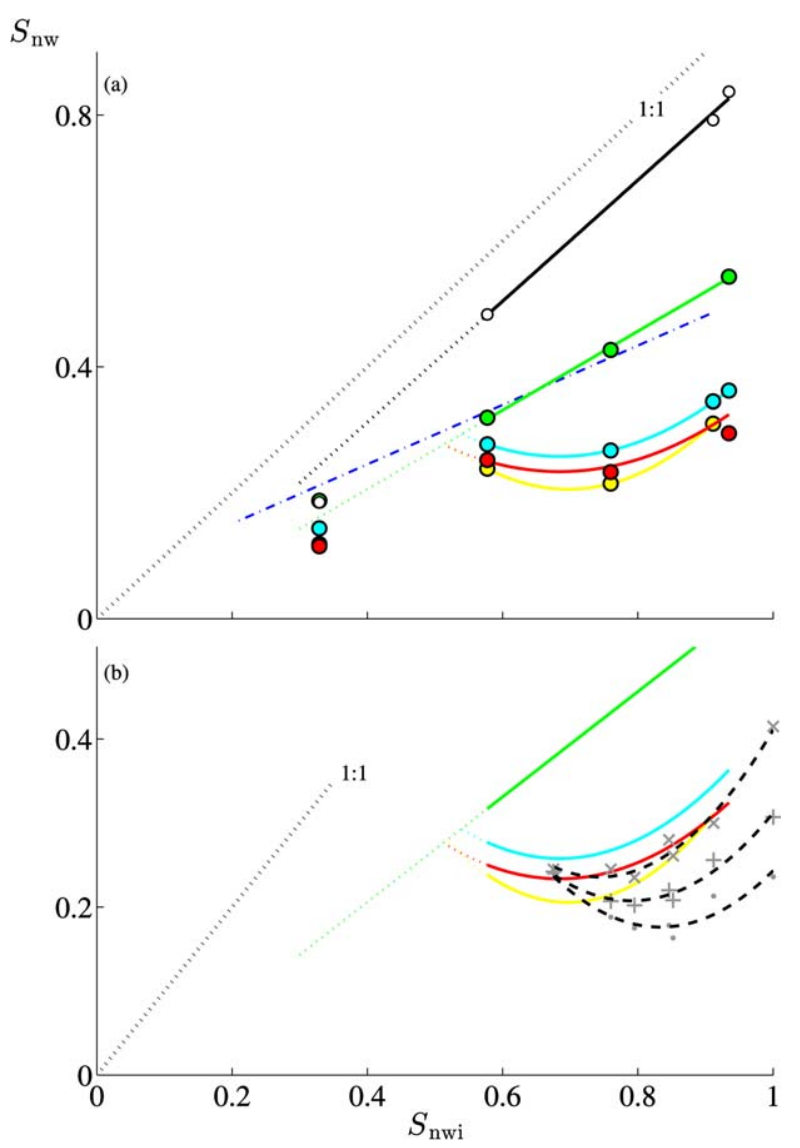

Figure 3. Remaining oil saturation as a function of its initial saturation under mixed-wet conditions: $S_{\mathrm{nw}}^{P_{c}=0}$ (open circles) and $S_{\mathrm{nw}}(n)$ for selected $n=0.7-1$ pv (green circles), 23-25 pv (cyan circles), 99-101 pv (red circles), and 193-217 pv (yellow circles). Solid lines are the line of best-fit to $S_{\mathrm{nw}}^{P_{c}=0}$ (black) and $S_{\mathrm{nw}}(1 \mathrm{pv})$ or the bestfit second-order polynomial to $S_{\mathrm{nw}}(n>20 \mathrm{pv})$, for $S_{\text {nwi }}>0.5$; see Table 4 for numerical values of the coefficients. The dash-dotted line in Figure $3 \mathrm{a}$ is equation (6), and depicts the residual saturation under water-wet conditions. Also shown in Figure $3 \mathrm{~b}$ are $S_{\mathrm{nw}}(n)$ measured at $n=1 \mathrm{pv}$ (crosses), $5 \mathrm{pv}$ (pluses), and $20 \mathrm{pv}$ (dots) in a mixed-wet sandstone by Salathiel [1973]; dashed lines are best-fit second-order polynomials (cf. Table 4). The data point for $\left(S_{\mathrm{nw}}, n\right)=(0.19,1 \mathrm{pv})$ at $S_{\mathrm{nwi}}=0.33$ overlaps with $S_{\mathrm{nw}}^{P_{c}=0}=0.18$ and can hardly be discerned in Figure $3 \mathrm{a}$. 


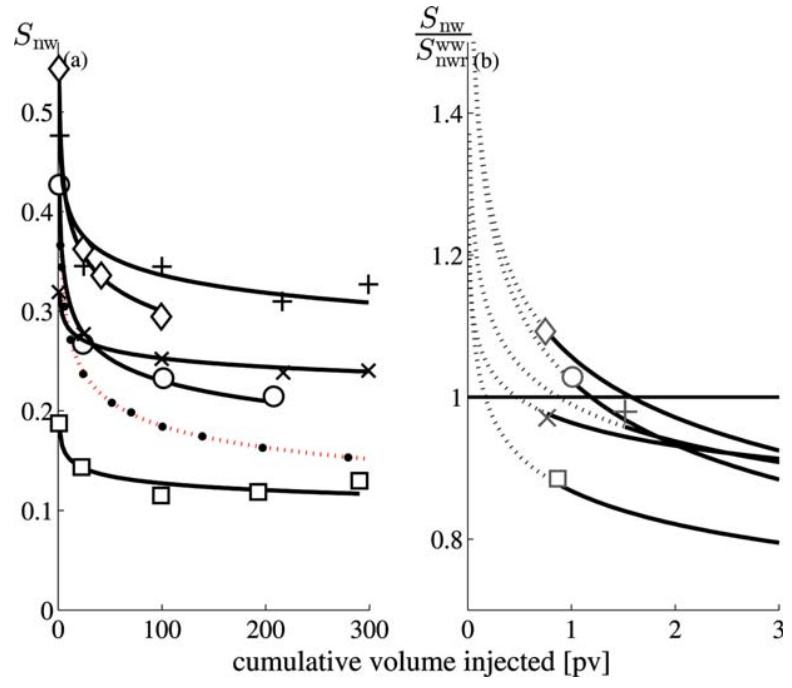

Figure 4. The evolution of the remaining oil saturation during waterflooding for $S_{\text {nwi }}=0.33$ (squares), 0.58 (crosses), 0.76 (circles), 0.91(pluses), 0.93(diamonds) (a) as $S_{\mathrm{nw}}$ and (b) in normalized form $S_{\mathrm{nw}} / S_{\mathrm{nwr}}^{\mathrm{ww}}$, where $S_{\mathrm{nwr}}^{\mathrm{ww}}$ is that predicted by equation (6). Solid lines are best-fit power functions (see Table 3). Also plotted in Figure 4a are $S_{\text {nw }}(n)$ in a mixed-wet sandstone reported in Salathiel [1973] (dots) and the corresponding best-fit power function $\left(S_{\mathrm{nw}}=\right.$ $0.425 n^{-0.181}$, dotted line).

continuously with increasing $S_{\text {nwi }}$ [Land, 1968]. Combined, these observations suggest that the concave-up quadratic $S_{\text {nw }}\left(S_{\text {nwi }}\right)$ profile may be a characteristic feature of mixed wettability that is conserved across a wide range of pore structure.

[32] The concave-up profile may be explained qualitatively as follows. As $S_{\text {nwi }}$ increases, an increasing number of pores and fractional surface area are modified to oilwetting. As a result, the connectivity of the oil during waterflooding in the form of films (or layers) along the oilwet patches of the grain surface is enhanced, offsetting the increase in $S_{\text {nwi }}$ such that $S_{\text {nw }}$ decreases with increasing $S_{\text {nwi }}$. As $S_{\text {nwi }}$ increases further, increasingly smaller pores and corners of larger pores become oil wet. However, because the capillary pressure distribution drives the injected brine through the centers of the larger pores, the additional oil in the smaller pores is largely retained during waterflooding and $S_{\text {nw }}$ increases with $S_{\text {nwi }}$.

[33] While this explanation appears plausible, a predictive quantification of this behavior poses a challenge for pore-scale modeling. Typically, pore network models incorporate wettability alteration by assigning grain surfaces in contact with the oil after primary drainage oil-wet characteristics. Then, by using the relative permeability predicted by the simulator, the evolution of the remaining oil saturation during waterflood may be predicted from a Buckley-Leverett analysis. Predictions vary considerably even for the same rock. For example, Valvatne and Blunt [2004]'s simulator yields a concave-up profile at the highest $S_{\text {nwi }}(\geq 0.69)$ in a pore network representative of Berea sandstone. In contrast, a more recently developed simulator predicts a monotonically increasing dependence [Ryazanov et al., 2009].
[34] Similarly, predictions for the endpoint (long-time) residual saturation display qualitatively different behavior: many scenarios yield a two-regime, concave-down dependence over the full range of $S_{\text {nwi }}$ [e.g., Blunt, 1997; Jackson et al., 2005], while others yield a constant saturation at high $S_{\text {nwi }}(\geq 0.8)$ [Ryazanov et al., 2009]. Interestingly, Blunt [1997] did predict a three-regime trend of residual oil saturation, an increase, then a decrease, and a more gradual increase, reminiscent of the present data, as the fraction of oil-wet pores in the network increased at a specific $S_{\text {nwi }}=0.89$. This was explained through the subtle interplay of oil layer connectivity, the connectivity of pores that remain water-filled after primary drainage, and the competing pore-scale displacement mechanisms. However, the same trend was not observed with increasing $S_{\text {nwi }}$.

[35] A close inspection of these studies suggests that it is indeed differences in the assigned contact angle distribution and its history, rather than the pore structure or topology, that give rise to the different trapping profiles. It is possible that accurately modeling the wettability alteration during the coreflood experiment, in a network representative of Indiana limestone, could reproduce the dependence on $S_{\text {nwi }}$ observed in the laboratory. This is a topic for future work using more sophisticated pore network models.

\section{Conclusions}

[36] The impact of wettability on capillary trapping was studied explicitly by measuring the remaining oil saturation established by waterflooding in the same rock under uniformly water-wet conditions and under mixed-wet conditions. Under water-wet conditions, the residual oil saturation increased linearly with its initial saturation. In contrast, under mixed-wet conditions, the remaining oil saturation displayed a non monotonic profile, with $S_{\text {nw }}$ increasing, decreasing, then increasing again as $S_{\text {nwi }}$ increases from 0 to $1 . S_{\text {nw }}$ at $S_{\text {nwi }}>0.5$ under mixed-wet conditions is accurately described by a concave-up quadratic function.

[37] Returning to our original motivation for this study, we now consider implications for EOR, in which waterflooding is performed to reduce $S_{\mathrm{nw}}$ at $n \leq O(1) \mathrm{pv}$. In a fractured reservoir, waterflooding drives flood water through the high permeability fractures, and oil remaining in the rock matrix is expelled predominantly by spontaneous imbibition of water from the fractures. Given $S_{\mathrm{nw}}^{P_{c}=0} \geq$ $S_{\text {nwr }}^{\mathrm{ww}}$ (Figure 3a), mixed-wet conditions are clearly unfavorable to recovery in such reservoirs. In contrast, in reservoirs without fractures, the remaining oil is displaced directly by the flood water. The present data suggest that at low $S_{\text {nwi }}$, mixed-wet conditions yield higher recovery than water-wet conditions, i.e., $S_{\mathrm{nw}}<S_{\mathrm{nwr}}^{\mathrm{ww}}$, even at $n<1$ pv (Figure $4 b$ ). This in turn suggests that the classic EOR technique of chemical flooding to revert the wettability of an oil reservoir to a more water-wetting state [Leach et al., 1962] may be detrimental in reservoirs where the initial (post-primary drainage) oil saturation was relatively low, e.g., reservoirs with a thick transition zone above the oil/water contact.

[38] One interesting question that emerges from the present study is the extent to which the concave-up quadratic correlation between remaining oil saturation and its 
initial saturation applies to different porous media. Most water-wet rocks can be classified into two categories based on their initial-residual saturation profile: the classic, Land [1968]-type nonlinear profile and a bilinear profile. The present study indicates that rocks in different categories under water-wet conditions can display similar profiles under mixed-wet conditions. Further insights require an extension of the present laboratory investigation to a suite of porous media representing a wide range of pore-scale and subpore-scale structure.

[39] Acknowledgments. This material is based on work supported by Qatar Petroleum, Shell and the Qatar Science and Technology Park under the Qatar Carbonates and Carbon Storage Research Centre. The authors gratefully acknowledge Koonyang Lee for the interfacial tension measurements. In addition, the authors thank Amer S. Syed and undergraduate students Josephine Herschan and Magali Christensen for their contribution to the coreflood experiments and Rink van Dijke, John Crawshaw, Alexander Wilson, and the three anonymous reviewers for their insightful comments and suggestions.

\section{References}

Amaefule, J. O., and L. L. Handy (1982), The effect of interfacial tensions on relative oil/water permeabilities of consolidated porous media, SPE J., 22(3), 371-381, doi:10.2118/9783-PA.

Anderson, W. G. (1986), Wettability literature survey part 1: Rock/oil/ brine interactions and the effects of core handling on wettability, J. Pet. Technol., 38(10), 1125-1144, doi:10.2118/13932-PA.

Anderson, W. G. (1987), Wettability literature survey-part 6: The effects of wettability on waterflooding, J. Pet. Technol., 39(12), 1605-1622, doi:10.2118/16471-PA.

Blunt, M. J. (1997), Pore level modeling of the effects of wettability, SPE J., 2(4), 494-510, doi:10.2118/38435-PA.

Chatzis, I., and N. Morrow (1984), Correlation of Capillary number relationships for sandstone, SPE J., 24(5), 555-562, doi:10.2118/10114-PA.

Churcher, P. L., P. R. French, J. C. Shaw, and L. L. Schramm (1991), Rock properties of Berea sandstone, Baker dolomite, and Indiana limestone, paper presented at International Symposium on Oilfield Chemistry, Soc. of Pet. Eng., Anaheim, Calif., 20-22 Feb., doi:10.2118/21044-MS

Dullien, F. A. L. (1991), Porous Media. Fluid Transport and Pore Structure, 2nd ed., Academic San Diego, Calif.

Dwarakanath, V., R. E. Jackson, and G. A. Pope (2002), Influence of wettability on the recovery of NAPLs from alluvium, Environ. Sci. Technol., 36(2), 227-231, doi:10.1021/es011023w.

El-Maghraby, R. M., and M. J. Blunt (2013), Residual $\mathrm{CO}_{2}$ trapping in Indiana limestone, Environ. Sci. Technol., 47(1), 227-233, doi:10.1021/ es304166u.

Espinoza, D. N., and J. C. Santamarina (2010), Water- $\mathrm{CO}_{2}$-mineral systems: Interfacial tension, contact angle, and diffusion-Implications to $\mathrm{CO}_{2}$ geological storage, Water Resour. Res., 46, W07537, doi:10.1029/ 2009WR008634.

Good, R. J., and R. S. Mikhail (1981), The contact angle in mercury intrusion porosimetry, Powder Technol., 29(1), 53-62, doi:10.1016/00325910(81)85004-8

Graue, A., B. G. Viksund, T. Eilertsen, and R. Moe (1999), Systematic wettability alteration by aging sandstone and carbonate rock in crude oil, J. Pet. Sci. Eng., 24(24), 85-97, doi:10.1016/S0920-4105(99)00033-9.

Hart, D. J., and H. F. Wang (1995), Laboratory measurements of a complete set of poroelastic moduli for Berea sandstone and Indiana limestone, $J$. Geophys. Res., 100(B9), 17,741-17,751, doi:10.1029/95JB01242.

Haynes, W. M. (2011), Concentrative properties of aqueous solutions: Density, refractive index, freezing point depression, and viscosity, in $C R C$ Handbook of Chemistry and Physics [online], edited by W. M. Haynes, 91st ed., CRC Press, Boca Raton, Fla.

Hilfer, R., and P.-E. Oren (1996), Dimensional analysis of pore scale and field scale immiscible displacement, Transp. Porous Media, 22(1), 53-72.

Iglauer, S., S. Favretto, G. Spinelli, G. Schena, and M. J. Blunt (2010), Xray tomography measurements of power-law cluster size distributions for the nonwetting phase in sandstones, Phys. Rev. E, 82, 056315, doi: 10.1103/PhysRevE.82.056315.
Iglauer, S., A. Paluszny, C. H. Pentland, and M. J. Blunt (2011), Residual $\mathrm{CO}_{2}$ imaged with X-ray micro-tomography, Geophys. Res. Lett., 38, L21403, doi:10.1029/2011GL049680.

Iglauer, S., M. A. Fern, P. Shearing, and M. J. Blunt (2012), Comparison of residual oil cluster size distribution, morphology and saturation in oilwet and water-wet sandstone, J. Colloid Interface Sci., 375(1), 187-192, doi: $10.1016 /$ j.jcis.2012.02.025.

Jackson, M. D., P. H. Valvatne, and M. J. Blunt (2005), Prediction of wettability variation within an oil/water transition zone and its impact on production, SPE J., 10(2), 184-195, doi:10.2118/77543-PA.

Jadhunandan, P. P., and N. R. Morrow (1995), Effect of wettability on waterflood recovery for crude-oil/brine/rock systems, SPE Reservoir Eng., 10(1), 40-46, doi:10.2118/22597-PA.

Jerauld, G. R., and J. J. Rathmell (1997), Wettability and relative permeability of Prudhoe Bay: A case study in mixed-wet reservoirs, SPE Reservoir Eng., 12(1), 58-65, doi:10.2118/28576-PA.

Johannesen, E. B., A. Graue, B. A. Baldwin, and D. P. Tobola (2007), Establishing mixed wet conditions in chalk-Emphasis on wettability alteration and oil recovery, paper presented at International Symposium, Soc. of Core Anal., Calgary, Alberta, Canada, 10-12 Sept.

Kaminsky, R., V. Bergeron, and C. J. Radke (1993), Thin films, asphaltenes, and reservoir wettability, Tech. Rep. LBL-34467, Lawrence Berkeley Lab., Berekeley, Calif., doi:10.2172/10194918.

Kestin, J., H. Khalifa, and R. Correia (1981), Tables of the dynamic and kinematic viscosity of aqueous $\mathrm{NaCl}$ solutions in the temperature range $20-150^{\circ} \mathrm{C}$ and the pressure range 0.1-35 MPa, J. Phys. Chem. Ref. Data, 10(1), 71-87.

Land, C. (1968), Calculation of imbibition relative permeability for twoand three-phase flow from rock properties, SPE J., 243, 149-156, doi: 10.2118/1942-PA.

Leach, R. O., O. R. Wagner, H. W. Wood, and C. F. Harpke (1962), A laboratory and field study of wettability adjustment in water flooding, J. Pet. Technol., 14(2), 206-212, doi:10.2118/119-PA.

Mair, R. W., G. P. Wong, D. Hoffmann, M. D. Hurlimann, S. Patz, L. M. Schwartz, and R. L. Walsworth (1999), Probing porous media with gas diffusion NMR, Phys. Rev. Lett., 83, 3324-3327, doi:10.1103/ PhysRevLett.83.3324.

Mungan, N. (1966), Interfacial effects in immiscible liquid-liquid displacement in porous media, SPE J., 6(3), 247-253, doi:10.2118/1442-PA.

Oak, M. J., L. E. Baker, and D. C. Thomas (1990), Three-phase relative permeability of Berea sandstone, J. Pet. Technol., 42(8), 1054-1061, doi: $10.2118 / 17370-P A$.

Øren, P.-E., S. Bakke, and O. J. Arntzen (1998), Extending predictive capabilities to network models, SPE J., 3(4), 324-336, doi:10.2118/52052PA.

Pentland, C. H., R. El-Maghraby, S. Iglauer, and M. J. Blunt (2011), Measurements of the capillary trapping of super-critical carbon dioxide in Berea sandstone, Geophys. Res. Lett., 38, L06401, doi:10.1029/ 2011 GL046683.

Powers, S. E., and M. E. Tamblin (1995), Wettability of porous media after exposure to synthetic gasolines, J. Contam. Hydrol., 19(2), 105-125, doi:10.1016/0169-7722(95)00008-J.

Powers, S. E., W. H. Anckner, and T. F. Seacord (1996), Wettability of NAPL-contaminated sands, J. Environ. Eng., 122(10), 889-896, doi:10.1061/(ASCE)0733-9372(1996)122:10(889).

Ryazanov, A. V., M. I. J. Dijke, and K. S. Sorbie (2009), Two-phase pore-network modelling: Existence of oil layers during water invasion, Transp. Porous Media, 80, 79-99, doi:10.1007/s11242-0099345-x.

Salathiel, R. A. (1973), Oil recovery by surface film drainage in mixedwettability rocks, SPE J., 25(10), 1216-1224, doi:10.2118/4104-PA.

Skauge, A., and B. Ottesen (2002), A summary of experimentally derived relative permeability and residual saturation on North Sea reservoir cores, paper presented at International Symposium, Soc. of Core Anal., Monterey, Calif., 23-25 Sept.

Stegemeier, G. L. (1977), Mechanism of entrapment and mobilization of oil in porous media, in Improved Oil Recovery by Surfactant and Polymer Flooding, edited by D. O. Shah and R. S. Schechter, pp. 55-91, Academic, New York.

Sutanto, E., H. T. Davis, and L. E. Scriven (1990), Liquid distributions in porous rock examined by cryo scanning electron microscopy, paper presented at Annual Technical Conference and Exhibition, Soc. of Pet. Eng., New Orleans, La., 23-26 Sept., doi:10.2118/20518-MS.

Tanino, Y., and M. J. Blunt (2012), Capillary trapping in sandstones and carbonates: Dependence on pore structure, Water Resour. Res., 48, W08525, doi:10.1029/2011WR011712. 
Taylor, J. R. (1997), An Introduction to Error Analysis. The Study of Uncertainties in Physical Measurements, 2nd ed., Univ. Sci. Books, Sausalito, Calif.

Valvatne, P. H., and M. J. Blunt (2004), Predictive pore-scale modeling of two-phase flow in mixed wet media, Water Resour. Res., 40, W07406, doi: 10.1029/2003WR002627.

Wang, F. H. L. (1988), Effect of wettability alteration on water/oil relative permeability, dispersion, and flowable saturation in porous media, SPE Reservoir Eng., 3(2), 617-628, doi:10.2118/15019-PA.

Wang, S., I. M. Edwards, and A. F. Clarens (2012), Wettability phenomena at the $\mathrm{CO}_{2}$-brine-mineral interface: Implications for geologic carbon sequestration, Environ. Sci. Technol., 47(1), 234-241, doi:10.1021/ es301297z.

Wardlaw, N. C., and R. P. Taylor (1976), Mercury capillary pressure curves and the intepretation of pore structure and capillary behaviour in reservoir rocks, Bull. Can. Pet. Geol., 24(2), 225-262.

Wardlaw, N. C., Y. Li, and D. Forbes (1987), Pore-throat size correlation from capillary pressure curves, Transp. Porous Med., 2(6), 597-614, doi:10.1007/BF00192157.

Winslow, D. N. (1978), The validity of high pressure mercury intrusion porosimetry, J. Colloid Interface Sci., 67(1), 42-47, doi:10.1016/00219797(78)90212-6
Wood, A. R., T. C. Wilcox, D. G. MacDonald, J. J. Flynn, and P. F. Angert (1991), Determining effective residual oil saturation for mixed wettability reservoirs: Endicott Field, Alaska, paper presented at Annual Technical Conference and Exhibition, Soc. of Pet. Eng., Dallas, Tex., 6-9 Oct., doi:10.2118/22903-MS.

Wu, Y., P. J. Shuler, M. Blanco, Y. Tang, and W. A. Goddard III (2008), An experimental study of wetting behavior and surfactant EOR in carbonates with model compounds, SPE J., 13(1), 26-34, doi:10.2118/99612PA.

Zeppieri, S., J. Rodríguez, and A. López de Ramos (2001), Interfacial tension of alkane + water systems, J. Chem. Eng. Data, 46(5), 1086-1088, doi: $10.1021 / \mathrm{je} 000245 \mathrm{r}$.

Zhou, X., N. R. Morrow, and S. Ma (2000), Interrelationship of wettability, initial water saturation, aging time, and oil recovery by spontaneous imbibition and waterflooding, SPE J., 5(2), 199-207, doi:10.2118/ 62507-PA.

Zhu, W., P. Baud, and T. Wong (2010), Micromechanics of cataclastic pore collapse in limestone, J. Geophys. Res., 115, B04405, doi:10.1029/ 2009JB006610. 